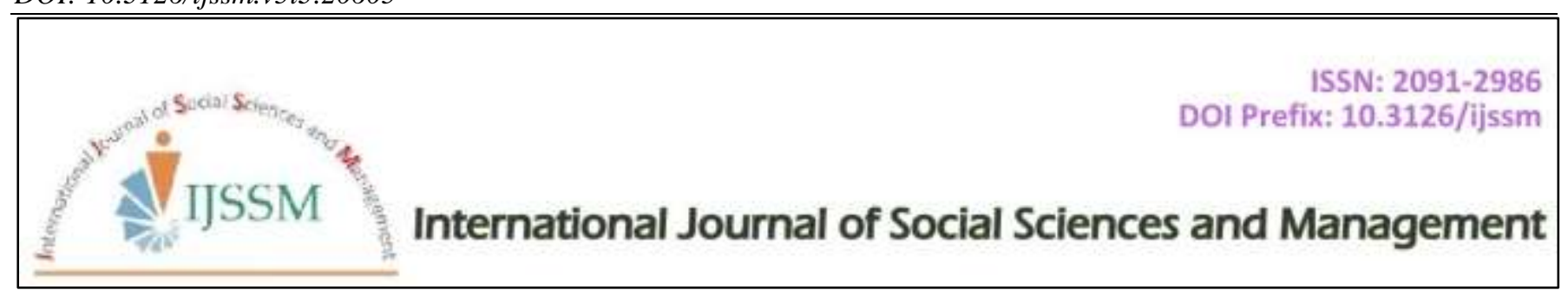

Research Article

\title{
Bioscience Subjects Background and Nursing Education
}

\author{
Rozia Malik $^{1}$, Muhammad Hussain ${ }^{1}$, Hajra Sarwer ${ }^{1}$, Muhammad Afzal ${ }^{1}$, Syed Amir Gilani ${ }^{2}$ \\ ${ }^{1}$ Lahore School of Nursing, The University of Lahore, Pakistan \\ ${ }^{2}$ Faculty of Allied Health Sciences (AHS), The University of Lahore, Pakistan
}

\begin{abstract}
Traditionally, Nursing students study human bioscience e.g. pathophysiology, microbiology, anatomy and physiology in their first and second year course. Nursing students are facing difficulties with bioscience learning. Hence, it's essential for nursing students to keep in mind that bioscience understanding is very important throughout the research, and clinical practice. The PURPOSE of this study was to assess BSN students' experiences regarding bioscience subject's background and nursing education. A cross-sectional analytic study was done among 183 BSN (Generic) students February 2018 to May 2018. Convenient sampling technique was used to collect the required sample size. Data on individual characteristics of Bioscience learning experiences was collected by distributing semi-structured questionnaire. Statistical tool SPSS 21.0 was used for the analysis of collected data. Person correlation test used to determine the relationship between variables. In this study majority of BSN (Generic) students were considered bioscience subjects more challenging and time consuming. About 45.36\% participants were agreed with there is more content required for bioscience compared with nursing subjects. BSN students $(59.56 \%)$ were reported that bioscience related to nursing practice to gain better understanding for assessment. Majority of participants were reported that bioscience subjects more difficult as compared to nursing subjects. Bioscience relationship with nursing practices significantly correlated with clinical-relevant employment. In this type of research the area of improvement have been reviewed further knowledge available for those who will conduct the research on this topic in future.
\end{abstract}

Keywords: Bioscience subjects; BSN (Generic); Clinical-relevant employment; Nursing Education; Nursing practices; Relationship.

\section{Introduction}

Traditionally, Nursing students study human bioscience e.g. pathophysiology, microbiology, anatomy and physiology in their first and second year course. Learning of these human bioscience and, in the long run, pharmacology, is vital to create the equipped and prepared nurses with imperative information and capacities that fundamental for high care quality and positive outcomes of patient (Smales, 2010). Hence, it's essential for nursing students to keep in mind that bioscience understanding is very important throughout the research, and clinical practice (Logan \& Angel, 2011). The joining of bioscience instruction inside nursing training has been testing (Taylor, Ashelford, Fell, \& Goacher, 2015). Many studied done on bioscience subject's importance in nursing profession with the purpose of improving the educational status. (Schaffer et al., 2014). In addition to, demographics of participant's highly influence on bioscience subjects understanding (Gordon, Hudson,

\section{Cite this article as:}

R. Malik et al. (2018) Int. J. Soc. Sc. Manage. Vol. 5, Issue-3: 163-169. DOI: 10.3126/ijssm.v5i3.20605

$1 *$ Corresponding author

Rozia Malik,

Lahore School of Nursing, The University of Lahore, Pakistan

Email: roziamalik55@gmail.com

Peer reviewed under authority of IJSSM

(C) 2018 International Journal of Social Sciences and Management

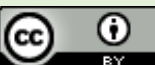

This is an open access article \& it is licensed under a Creative Commons Attribution 4.0 International License (https://creativecommons.org/licenses/by/4.0/)

Full text of this paper can be downloaded online at www.ijssm.org/ \&http://nepjol.info/index.php/IJSSM/issue/archive 
Plenderleith, Fisher, \& Craft, 2017). Furthermore, course content of bioscience subjects with nursing subjects conveyed to nursing students, to catch the best understanding and create inspiration for bioscience learning among nursing students (Evans et al., 2013). However, Nurses must have adequate knowledge and practices in bioscience subjects which is clearly related to nursing practices like microbiology to perform numerous parts inside clinical nursing practice (Durrant et al., 2017). Moreover, the nursing work forces requires an undeniably complex learning base to guarantee good patient outcomes and responsibility for training. (Owens \& Moroney, 2017). The aim of nursing education is to develop the nursing profession as well as required. Different approaches used to upraise the advancement and to clear up the professional role (Jack et al., 2017).Furthermore, a Study propose that more bioscience content needed in nursing education, clear terms and continue activities to enhance the review of bioscience are fundamental for students of nursing (Doggrell \& Schaffer, 2016). In the same way, bioscience subject learning is closely linked with nursing education. Secondary school science studied play an important role in understanding of bioscience subjects. In USA, undergraduates are required to must have a fundamental information of science, systems of life and physiology to be recognized into the courses of nursing degree. Somewhere else it is not generally the case, and this is recorded all around that the students of nursing are battling with bioscience subjects in the UK and Australia (McVicar et al., 2015). Moreover, some nursing undergraduates encounter difficulties and tensions when learning bio-science subjects at college/University. Bioscience has been distinguished as a part of studies that nursing students battling in tertiary establishments to learn and after that application of this knowledge to the clinical practice. Various issues have been distinguished and investigated that may add to this poor comprehension and maintenance (Bakon et al., 2016). Additionally, a study reported that early learning of bioscience subject e.g. starting testing of microbiology was very low by the nursing undergraduates. There was no lost review of early on microbiology examination with the time. In these cases we demonstrate lost review of the gastrointestinal physiology for nursing undergraduates in this study (Doggrell \& Schaffer, 2016). In spite of the fact that a comprehension of bioscience is important clearly, a few investigations have demonstrated that nursing students' are regularly on edge about considering bioscience subjects, however in any case value the significance and relevance of it to their practices (Davis, 2010). Despite the fact that nursing training has changed, there have been much more prominent changes in the profession of nursing. Nurses are currently anticipated that would be self-sufficient professionals, who can settle on choices about patient care and work as individuals from an interdisciplinary group. Recently, Two Australian examinations have likewise discovered that nursing understudies have negative dispositions towards bioscience (Koch et al., 2010). Regardless of the way that training of nurses has changed. Nurses are now anticipated that would act naturally overseeing experts, who can settle on new steps about the care of patients and participate as people from the multidisciplinary team. Nursing students acknowledged and value that bioscience subjects is a key that benefactor with nursing learning, and the utilization of this information to their training to enhances understanding consideration (Craft et al., 2013).

\section{Review of Literature}

Bioscience learning prepares nursing students with the basic and fundamental knowledge that is useful to improve patient safety and clinical practice. Be that as it may, while it could be assumed that there is a direct relevance between bioscience subjects and practices of nursing, the questions stay about what content of bioscience ought to be educated (Johnston et al., 2015). It has been recommended that teaching needs of bioscience subjects have a great connection with the clinical practice (McVicar et al., 2015). Furthermore, a study results shows that the participant's age have an impact on bioscience learning. This study found that the age groups of $20-30$ year, about $53.2 \%$ of the all respondents, with the comparison of aged students, bioscience subjects perceived to be difficult altogether. (Salamonson et al., 2013). Majority of students of nursing programme are facing difficulties with learning bioscience subjects. (Craft, Hudson, Plenderleith, Wirihana, \& Gordon, 2013). Round about half of the all nursing students agreed that bioscience subjects are unclear, difficult, and also have more content rather than the nursing subjects (Craft et al., 2017). As well as, the nursing students of final year, declared that the subjects of bioscience remain tricky all through the degree. The greater part of nursing students reported that bioscience subjects frames establishment of the nursing practice, $76.2 \%$ participants shown agreement. They still wanted the better comprehension of bioscience, $73.8 \%$ respondents shown agreement (Gordon et al., 2017). Likewise, Gordon et al. proposed that about $65.9 \%$ nursing students' encountered the subjects of bioscience are require more efficient work rather than the nursing subjects. $73.8 \%$ respondents would like the proper learning of bioscience subjects and $76.2 \%$ respondents' understood that the learning of bioscience subjects creates the strong basics regarding the practice of nurses (Gordon et al., 2017). Furthermore, study results revealed that some issues were encountered of the nursing understudies with the bioscience, physiology, and organic chemistry subjects. Here is the most essential factor for instructors to recognize the most ideal approach that amend for these circumstances. The additional study results also recommend that the understudies need additional materials, assets and direction when contemplating bioscience subjects (Durai et al., 
2012). In addition to, it is good and empowering that greater part of nursing students' (97\%) saw that it was important to have proper learning of the subjects of bioscience for practicing nurses. (Friedel \& Treagust, 2005). In the same way, the problem of science for entry requirements shows different views along the institutions. The utilization of bioscience knowledge to practices of nursing is much important that needs inside every nursing educational modules (Taylor et al., 2015).

\section{Methodology}

\section{Study Setting}

the study was conducted at Lahore School of Nursing (LSN), The University of Lahore (UOL) and College of Nursing AIMC/Jinnah Hospital Lahore.

\section{Study Design}

Descriptive cross-sectional analytic study design was used.

\section{Study Population}

Data was collected from BSN (Generic) students (108) of Lahore School of Nursing (LSN), The University of Lahore (UOL) and BSN (Generic) students (130) of College of Nursing (CON), Jinnah Hospital Lahore. Total study population was $238 \mathrm{BSN}$ students.

\section{Sampling Method}

Convenient sampling technique was used.

\section{Data Collection Method and Procedure}

Data was collected by distributing questionnaire among nursing students. Questionnaire adopted from a study conducted by (Gordon et al., 2017). This questionnaire contains questions on students learning of bioscience content, bioscience learning difficulty, relationship of bioscience to nursing practice, and approaches to bioscience learning.

\section{Data Analysis}

Data was analysed by using SPSS version 21. For individual item means, median, mode frequency distribution and standard deviations were reported. Chi-square test was applied to measure the associations existed between the demographic variables and individual items. $\mathrm{P}$ value is considered $\mathrm{P}<0.05$ that is significant statistically for the all analyses. Relationship of clinical relevance employment with subscale "bioscience subject's relationship to nursing practices" was checked by Pearson correlation test.

\section{Ethical Consideration}

Permission was taken from institutional review board (IRB) committee of university of Lahore. Permission was taken from HOD of LSN, UOL and Principal of College of Nursing, Jinnah Hospital Lahore. A consent form was attached with each questionnaire for respondents. Confidentiality and privacy of participants was maintained.

\section{Study Duration}

This study approximately completed in 4 months from February, 2018 to May, 2018.

\section{Results}

This chapter consists of the results and statistical analysis summary that was used to assess the hypothesis and research objectives. This chapter divided into three parts. First section consist on descriptive statistics of demographics of the participants. Second part consist of descriptive statistics of participant's responses on bioscience subjects experiences. And the last part consist on the association of respondents demographics with the bioscience subjects learning experiences and variable correlations.

\section{Profile of Respondents}

Table 1 shows the participant's demographic data. Majority of participants $(80.87 \%)$ were from the age group of 17-22 years, $(n=148)$ and only 19.13 were from the age group of 23-28 years $(n=35)$, no any participant above 28 years. Majority of participants $(91.80 \%)$ were female $(n=168)$ and only $8.197 \%$ were male $(n=15) .54 .10 \%(n=99)$ participants got highest marks in biology, $24.59 \%(n=45)$ in chemistry and only $21.31 \%(n=39)$ got highest marks in physics. Most of the participant's 50.27\% $(\mathrm{n}=92)$ were from $1^{\text {st }}$ year, $29.51 \%(\mathrm{n}=54)$ from $2^{\text {nd }}$ year, $11.48 \%(\mathrm{n}=$ $21)$ from $3^{\text {rd }}$ year and $8.74 \%(n=16)$ from the $4^{\text {th }}$ year of 4 years BSN programme. Only $20.77(n=38)$ participants were assistant in nursing, majority of participant's 61.75 $(n=113)$ were enrolled nurses and about $17.49(n=32)$ had no any clinical employment.

Table 1: Demographic Data

\begin{tabular}{lll}
\hline Demographic characteristics & & $f(\%)$ \\
\hline Age & $17-22$ y & $148(80.9)$ \\
& $23-28$ y & $35(19.1)$ \\
& $>28$ y & $0(0)$ \\
& Total & $\mathbf{1 8 3}(\mathbf{1 0 0 . 0})$ \\
Sex & Male & $15(8.2)$ \\
& Female & $168(91.8)$ \\
Secondary school study & Total & $\mathbf{1 8 3}(\mathbf{1 0 0 . 0})$ \\
highest mark in & Biology & $99(54.1)$ \\
& Chemistry & $45(24.6)$ \\
Year in 4 year BSN & Physics & $39(21.3)$ \\
programme & Total & $\mathbf{1 8 3}(\mathbf{1 0 0 . 0})$ \\
& $1^{\text {st }}$ year & $92(50.3)$ \\
& $2^{\text {nd }}$ year & $54(29.5)$ \\
& $3^{\text {rd } \text { year }}$ & $21(11.5)$ \\
Clinically-relevant & $4^{\text {th }}$ year & $16(8.7)$ \\
employment & Total & $\mathbf{1 8 3}(\mathbf{1 0 0 . 0})$ \\
& Assistant in & $38(20.8)$ \\
& nursing & \\
& Enrolled nurses & $113(61.7)$ \\
& No clinical & $32(17.4)$ \\
& employment & \\
& Total & $\mathbf{1 8 3}(\mathbf{1 0 0 . 0})$ \\
\hline & & \\
& &
\end{tabular}


Table 2 shows that Negative Statistically significant relationship was found between clinical-relevant employment and bioscience relationship with nursing practices.

Table 3 shows chi-square test result which was performed to test the association between participant's demographics and subscales. Participant's age was significantly associated with student's learning of bioscience content, bioscience learning difficulties and approaches to learning bioscience $(\mathrm{P}<0.05)$. Sex association with four subscales was not statistically significant. Secondary school study highest marks association with student's learning of bioscience content was statistically significant. There was no association of Secondary school study highest marks association with other three subscales. Year in 4 year BSN programme association with Bioscience difficulties and approaches to bioscience learning was statistically significant but not significant with the other two subscales. Clinical-relevant employment statistically significant with bioscience difficulties. There was no association with other three subscales.

Table 2: Correlations

\begin{tabular}{llll}
\hline & & $\begin{array}{l}\text { Clinically-Relevant } \\
\text { Employment }\end{array}$ & $\begin{array}{l}\text { Bioscience relationship to } \\
\text { Nursing practices }\end{array}$ \\
\hline $\begin{array}{llll}\text { Clinically-relevant } \\
\text { employment }\end{array}$ & $\begin{array}{l}\text { Pearson } \\
\text { Correlation } \\
\end{array}$ & 1 & -.144 \\
& Sig. (2-tailed) & & .041 \\
Bioscience relationship to & Pearson & 183 & 183 \\
Nursing practices & Correlation & -.144 & 1 \\
& Sig. (2-tailed) & .041 & \\
& $\mathrm{~N}$ & 183 & 183 \\
\hline
\end{tabular}

Table 3: Chi-Square Tests

\begin{tabular}{|c|c|c|c|}
\hline Variables & Value $\left(\chi^{2}\right)$ & Df & Sig. (2-sided) \\
\hline \multicolumn{4}{|l|}{ *Age } \\
\hline Learning of bioscience content & $36.410^{\mathrm{a}}$ & 29 & .016 \\
\hline Bioscience difficulties & $43.098^{\mathrm{a}}$ & 21 & .003 \\
\hline Relationship of bioscience to nursing practices & $19.717^{\mathrm{a}}$ & 18 & .349 \\
\hline Approaches to bioscience learning & $28.260^{\mathrm{a}}$ & 12 & .005 \\
\hline \multicolumn{4}{|l|}{ *Sex } \\
\hline Learning of bioscience content & $31.464^{\mathrm{a}}$ & 29 & .112 \\
\hline Bioscience difficulties & $20.871^{\mathrm{a}}$ & 21 & .467 \\
\hline Relationship of bioscience to nursing practices & $27.865^{\mathrm{a}}$ & 18 & .064 \\
\hline Approaches to bioscience learning & $15.031^{\mathrm{a}}$ & 12 & .240 \\
\hline \multicolumn{4}{|l|}{ *Secondary school study highest marks in } \\
\hline Learning of bioscience content & $77.334^{\mathrm{a}}$ & 58 & .046 \\
\hline Bioscience difficulties & $43.189^{\mathrm{a}}$ & 42 & .420 \\
\hline Relationship of bioscience to nursing practices & $41.508^{\mathrm{a}}$ & 36 & .223 \\
\hline Approaches to bioscience learning & $27.239^{\mathrm{a}}$ & 24 & .293 \\
\hline \multicolumn{4}{|l|}{ *Year in 4 year BSN programme } \\
\hline Learning of bioscience content & $90.892^{\mathrm{a}}$ & 87 & .366 \\
\hline Bioscience difficulties & $80.402^{\mathrm{a}}$ & 63 & .046 \\
\hline Relationship of bioscience to nursing practices & $38.477^{\mathrm{a}}$ & 54 & .941 \\
\hline Approaches to bioscience learning & $63.885^{\mathrm{a}}$ & 36 & .003 \\
\hline \multicolumn{4}{|l|}{ *Clinical-relevant employment } \\
\hline Learning of bioscience content & $63.921^{\mathrm{a}}$ & 58 & .276 \\
\hline Bioscience difficulties & $56.427^{\mathrm{a}}$ & 42 & .006 \\
\hline Relationship of bioscience to nursing practices & $36.824^{\mathrm{a}}$ & 36 & .431 \\
\hline Approaches to bioscience learning & $25.434^{\mathrm{a}}$ & 24 & .338 \\
\hline
\end{tabular}


Table 4: BSN (Generic) students' responses to questionnaire. ( $n=183)$

\begin{tabular}{|c|c|c|c|c|c|}
\hline Descriptor & $\begin{array}{l}\text { SDA } \\
f(\%)\end{array}$ & $\begin{array}{l}\text { DA } \\
f(\%)\end{array}$ & $\begin{array}{l}\mathrm{N} \\
f(\%)\end{array}$ & $\begin{array}{l}\text { A } \\
f(\%)\end{array}$ & $\begin{array}{l}\text { SA } \\
f(\%)\end{array}$ \\
\hline \multicolumn{6}{|l|}{ 1. Students' learning of bioscience content. } \\
\hline $\begin{array}{l}\text { I was not expecting to study this amount of bioscience when I enrolled in } \\
\text { nursing. }\end{array}$ & $\begin{array}{l}31 \\
(16.9)\end{array}$ & $\begin{array}{l}53 \\
(29.0)\end{array}$ & $\begin{array}{l}32 \\
(17.5)\end{array}$ & $\begin{array}{l}40 \\
(21.9)\end{array}$ & $\begin{array}{l}27 \\
(14.8)\end{array}$ \\
\hline $\begin{array}{l}\text { The bioscience units are the most difficult that I am undertaking during my } \\
\text { course. }\end{array}$ & $\begin{array}{l}29 \\
(15.8)\end{array}$ & $\begin{array}{l}44 \\
(24.0)\end{array}$ & $\begin{array}{l}45 \\
(24.6)\end{array}$ & $\begin{array}{l}45 \\
(24.6)\end{array}$ & $\begin{array}{l}20 \\
(10.9)\end{array}$ \\
\hline $\begin{array}{l}\text { Nursing lecturers should teach the bioscience units (rather than science } \\
\text { lecturers). }\end{array}$ & $\begin{array}{l}29 \\
(15.8)\end{array}$ & $\begin{array}{l}19 \\
(10.4)\end{array}$ & $\begin{array}{l}36 \\
(19.7)\end{array}$ & $\begin{array}{l}54 \\
(29.5)\end{array}$ & $\begin{array}{l}45 \\
(24.6)\end{array}$ \\
\hline $\begin{array}{l}\text { I am concerned about passing bioscience, as it might delay my course } \\
\text { completion }\end{array}$ & $\begin{array}{l}22 \\
(12.0)\end{array}$ & $18(9.8)$ & $\begin{array}{l}38 \\
(20.8)\end{array}$ & $\begin{array}{l}72 \\
(39.3)\end{array}$ & $\begin{array}{l}33 \\
(18.0)\end{array}$ \\
\hline Bioscience subjects are harder than my nursing subjects & $\begin{array}{l}28 \\
(15.3)\end{array}$ & $\begin{array}{l}26 \\
(14.2)\end{array}$ & $\begin{array}{l}31 \\
(16.9)\end{array}$ & $\begin{array}{l}54 \\
(29.5)\end{array}$ & $\begin{array}{l}44 \\
(24.0)\end{array}$ \\
\hline The language of bioscience makes it easy to learn & $13(7.1)$ & $18(9.8)$ & $\begin{array}{l}35 \\
(19.1)\end{array}$ & $\begin{array}{l}67 \\
(36.6)\end{array}$ & $\begin{array}{l}50 \\
(27.3)\end{array}$ \\
\hline The teaching style used in bioscience subjects makes them easy to learn & $17(9.4)$ & $15(8.2$ & $\begin{array}{l}27 \\
(14.8)\end{array}$ & $\begin{array}{l}65 \\
(35.5)\end{array}$ & $\begin{array}{l}59 \\
(32.2)\end{array}$ \\
\hline $\begin{array}{l}\text { There is more content required for bioscience compared with nursing } \\
\text { subjects }\end{array}$ & $\begin{array}{l}25 \\
(13.7)\end{array}$ & $\begin{array}{l}36 \\
(19.7)\end{array}$ & $\begin{array}{l}39 \\
(21.3)\end{array}$ & $\begin{array}{l}51 \\
(27.9)\end{array}$ & $\begin{array}{l}32 \\
(17.5)\end{array}$ \\
\hline $\begin{array}{l}\text { I think there is adequate university support to allow me to do well in } \\
\text { bioscience units }\end{array}$ & $9(4.9)$ & $\begin{array}{l}29 \\
(15.8)\end{array}$ & $\begin{array}{l}44 \\
(24.0)\end{array}$ & $\begin{array}{l}78 \\
(42.6)\end{array}$ & $\begin{array}{l}30 \\
(12.6)\end{array}$ \\
\hline Exam-based assessments are more difficult than other assessment types & $16(8.7)$ & $\begin{array}{l}27 \\
(14.8)\end{array}$ & $\begin{array}{l}37 \\
(20.2)\end{array}$ & $\begin{array}{l}73 \\
(39.9)\end{array}$ & $\begin{array}{l}30 \\
(16.4)\end{array}$ \\
\hline $\begin{array}{l}\text { The time I spend studying bioscience is more than I spend on nursing } \\
\text { subjects }\end{array}$ & $13(7.1)$ & $\begin{array}{l}26 \\
(14.2)\end{array}$ & $\begin{array}{l}32 \\
(17.5)\end{array}$ & $\begin{array}{l}67 \\
(36.6)\end{array}$ & $\begin{array}{l}45 \\
(24.6)\end{array}$ \\
\hline
\end{tabular}

\section{Bioscience difficulty
Bioscience consists of mathematics, making it difficult to understand}

I have learnt body organ systems, but have not yet well understood how they are integrated

Bioscience is difficult because concepts are difficult to visualize

$\begin{array}{lllll}29 & 31 & 31 & 45 & 38 \\ (15.8) & (16.9) & (16.9) & (29.5) & (20.8) \\ 19 & 37 & 33 & 54 & 40 \\ (10.4) & (20.2) & (18.0) & (19.5) & (21.9) \\ 19 & 31 & 48 & 58 & 27 \\ (10.4) & (16.9) & (26.2) & (31.7) & (14.8) \\ 6(3.3) & 20 & 36 & 72 & 49 \\ & (10.9) & (19.7) & (39.3) & (26.8) \\ 28 & 25 & 40 & 52 & 38 \\ (15.3) & (13.7) & (21.9) & (28.4) & (20.8) \\ 21 & 26 & 36 & 57 & 43 \\ (11.5) & (14.2) & (19.7) & (31.1) & (23.5) \\ 17(9.3) & 17(9.3) & 30 & 63 & 56 \\ & & (16.4) & (34.4) & (30.6)\end{array}$

I feel confident that I will be able to explain the biologic basis of nursing decisions

It is hard to combine bioscience knowledge to make sense of what is wrong with patients

The topics taught within bioscience should be taught in nursing in the same week

I would like to have a better knowledge of bioscience than I have at present

3. Relationship of bioscience to nursing

Practice.

I relate bioscience to nursing practice to gain a better understanding for assessment

It is easy to see how bioscience subjects relate to nursing practice

\begin{tabular}{lllll}
20 & 21 & 33 & 73 & 36 \\
$(10.9)$ & $(11.5)$ & $(18.0)$ & $(39.9)$ & $(19.7)$ \\
$11(6.0)$ & 24 & 42 & 71 & 35 \\
& $(13.1)$ & $(23.0)$ & $(38.8)$ & $(19.1)$ \\
4 & 23 & 34 & 85 & 37 \\
$(2.2)$ & $(12.6)$ & $(18.6)$ & $(46.4)$ & $(20.2)$ \\
$15(8.2)$ & $14(7.7)$ & 24 & 80 & 50 \\
& & $(13.1)$ & $(43.7)$ & $(27.3)$ \\
$17(9.3)$ & $17(9.3)$ & 27 & 75 & 47 \\
& & $(14.8)$ & $(41.0)$ & $(25.7)$ \\
& & & & \\
19 & 30 & 34 & 69 & 31 \\
$(10.4)$ & $(16.4)$ & $(18.6)$ & $(37.7)$ & $(16.9)$ \\
43 & 33 & 30 & 53 & 24 \\
$(23.5)$ & $(18.0)$ & $(16.4)$ & $(29.0)$ & $(13.1)$ \\
22 & 21 & 39 & 56 & 45 \\
$(12.0)$ & $(11.5)$ & $(21.3)$ & $(30.6)$ & $(24.6)$ \\
\hline
\end{tabular}

An understanding of bioscience forms the foundation of nursing practice

When I reach the workplace, I will be able to see why bioscience is important to nursing

It would assist my understanding if nursing lecturers related more to

Bioscience

4. Approaches to Bioscience learning.

I am comfortable with the level of detail taught in bioscience subjects

I can learn bioscience by memorizing, without needing to understand

I think about bioscience as organ systems, rather than general concepts when studying 


\section{Discussion}

This study assessed the experiences with bioscience subjects learning among BSN (Generic) students of LSN, UOL and CON/AIMC, Jinnah Hospital Lahore. Bioscience learning is important to understand the entire process of clinical nursing practices. According to our study findings majority of participants were agreed with there was more content of bioscience subjects needed. Majority of BSN students experienced with bioscience learning in nursing education was most time consuming and difficult to understand. As well as 58.9\% students this approves by findings from another study that presented that bioscience was demanding for students studying earlier in their degrees (Craft et al., 2017). The study findings showed that BSN student's considered that the bioscience subjects difficult as compared to their nursing subjects. As a study findings revealed that the undergraduate students of BSN who had completed the bioscience subjects component of their studies rated bioscience content difficult, and that the approach to learning bioscience was challenging (Gordon $e t$ al., 2017). However, the $1^{\text {st }}$ and $2^{\text {nd }}$ year students highly rated that the bioscience subjects more difficult and time consuming as compared with nursing subjects. As this study BSN students experiences with bioscience learning confirming that the subjects of bioscience remain tough and problematic during the BSN programme. Our study findings are in agreement with the results of previous study that first year BSN students have been shown to have difficulty with bioscience (Craft et al., 2017). The majority of participants reported that bioscience forms the foundation of nursing practice (agreed or strongly agreed), but they wanted a better understanding of bioscience (agreed or strongly agreed). Regardless of the rating the relationship of bioscience to nursing practice decidedly, more than half of BSN students agreed for that bioscience instructors expected to relate bioscience with nursing practices while lecturing and it would increase the understanding of if nursing lectures related more to bioscience. According to the McVicar et al (2015) nursing lectures have insufficient understanding of bioscience and its clinical relevance. Furthermore, 57.9\% respondents positively rated (agree or strongly agree) that it is easy to see how bioscience related to the nursing practices. This was reflected in nursing student's view about their perceptions of working environment, as about nine out of 10 nursing students agreed that they would have the capacity to see the clinical relevance of bioscience (Friedel \& Treagust, 2005). Results of the correlations analyses (Table \# 3) shows the clinical relevance employment relationship with bioscience relationship to nursing practices. Chi-square test used to check the participants demographics association with their experiences of bioscience subjects learning (Table \# 4, 5). Age and clinical relevance employment showed the statistically significant values $(\mathrm{P}<0.05)$. These findings confirmed by a previous study results, participants demographics influenced on their bioscience learning (Salamonson et al., 2013). Furthermore, this study results showed that $2^{\text {nd }}$ and $3^{\text {rd }}$ year BSN students with highest marks in biology had a better understanding of bioscience and how it relates to nursing practices. Experiences of BSN Students during their clinical placement showed that bioscience directly linked to nursing practices as $59.6 \%$ students agreed with "I relate bioscience to nursing practice to gain a better understanding for assessment". As well as $58.9 \%$ students showed agreement for that "It is easy to see how bioscience subjects relate to nursing practice". Our study result findings conformed by the result findings of a previous study which revealed about the bioscience relationship to nursing practice was highly rated than the other constructs (Gordon et al., 2017).

\section{Conclusion}

The current study done to assessed the BSN student's experiences of bioscience subjects learning and its association to their demographics at LSN, UOL and CON, AIMC Jinnah Hospital Lahore, Pakistan. The study findings shows the positive correlation of clinical relevance employment with bioscience subjects relationship to nursing practices and one variable shows statistically significance value $(\mathrm{P}<0.05)$. Participant's demographics had influence on their bioscience subjects learning and statistically significant. It is indicated by the study findings that the nursing instructors needs to work more to make sure the better understanding of bioscience subjects and clinical relevance by the better integration of bioscience. This would involve change of current educational modules to adjust bioscience subjects with clinical practice subjects that help nursing practice in the last years.

\section{Limitations}

This study done within a short period of time and on only two nursing institutes of Punjab (LSN, UOL and CON, JHL). Its findings cannot be generalizable to the whole Pakistan nurses experiences with bioscience. The current study only focused on the BSN (Generic) student's experiences with bioscience subjects learning. The factors affecting on their bioscience learning not clearly founded. Further studies in this area are required to identify the factors affecting on the nursing students learning of bioscience subjects and its utilization on clinical workplace.

\section{Acknowledgement}

The authors thankful to the faculty of LSN, The University of Lahore and College of Nursing/AIMC Jinnah Hospital Lahore and study contributors.

\section{References}

Bakon S, Craft J, Christensen M and Wirihana L (2016). Can active learning principles be applied to the bioscience 
assessments of nursing students? A review of the literature. Nurse education today 37: 123-127.

Craft J, Hudson P, Plenderleith M, Wirihana L and Gordon C (2013) Commencing nursing students' perceptions and anxiety of bioscience. Nurse education today 33(11): 1399-1405.

Craft JA, Hudson PB, Plenderleith MB and Gordon CJ (2017) Enrolled nurses entering undergraduate studies at second year to become registered nurses-A mixed methods study on commencing perceptions of bioscience. Collegian 24(4): 317-324.

Davis GM (2010) What is provided and what the registered nurse needs-bioscience learning through the pre-registration curriculum. Nurse education today, 30(8): 707-712.

Dictionary O (2017) British and World English: Oxford Dictionary.

Doggrell SA \& Schaffer S (2016) Lack of recall of bioscience knowledge by nursing students. Paper presented at the Proceedings of the Australian Conference on Science and Mathematics Education.

Durai RPR, Hassan H, Abdullah NA, Panduragan SL \& Mat S (2012) An exploration of issues relating to Medical Science subjects: nursing students' perception and experience in Universiti Kebangsaan Malaysia Medical Centre. Procedia-Social and Behavioral Sciences 60: 8589.

Durrant RJ, Doig AK, Buxton RL \& Fenn JP (2017) Microbiology Education in Nursing Practice. Journal of microbiology \& biology education 18(2).

Evans S, Berry C \& Mate KE (2013) Targeting the biosciencepractice nexus to facilitate learning in first year nursing students. Paper presented at the proceedings of the Australian conference on science and mathematics education (formerly UniServe science conference).

Friedel JM \& Treagust DF (2005) Learning bioscience in nursing education: perceptions of the intended and the prescribed curriculum. Learning in Health and Social Care 4(4): 203216.

Gordon CJ \& Hughes VK (2013) Creating relevance and credibility: New approaches for bioscience education in pre-registration nursing curriculum. International Journal of Innovation in Science and Mathematics Education 21(2).

Gordon CJ, Hudson PB, Plenderleith MB, Fisher M \& Craft JA (2017) Final year Australian nursing students' experiences with bioscience: A cross-sectional survey. Nursing \& health sciences 19(1): 22-28.
Jack K, Hamshire C \& Chambers A (2017) The influence of role models in undergraduate nurse education. Journal of clinical nursing 26(23-24): 4707-4715.

Jackson D, Hutchinson M, Everett B, Mannix J, Peters K, Weaver R \& Salamonson Y (2011) Struggling for legitimacy: Nursing students' stories of organisational aggression, resilience and resistance. Nursing Inquiry 18(2): 102-110.

Johnston A, Hamill J, Barton M, Baldwin S, Percival J, WilliamsPritchard G, . . . Todorovic M (2015) Student learning styles in anatomy and physiology courses: Meeting the needs of nursing students. Nurse education in practice 15(6): 415-420.

Koch J, Andrew S, Salamonson Y, Everett B \& Davidson PM (2010). Nursing students' perception of a web-based intervention to support learning. Nurse education today 30(6): 584-590.

Kolb DA (1975) Towards an applied theory of experiential learning. Theory s of Group Processes 33-58.

Logan PA \& Angel L (2011) Nursing as a scientific undertaking and the intersection with science in undergraduate studies: implications for nursing management. Journal of Nursing Management 19(3): 407-417.

McVicar A, Andrew S \& Kemble R (2015) The 'bioscience problem'for nursing students: an integrative review of published evaluations of Year 1 bioscience, and proposed directions for curriculum development. Nurse education today 35(3): 500-509.

Owens A \& Moroney T (2017) Shifting the load: Improving bioscience performance in undergraduate nurses through student focused learning. Collegian 24(1): 37-43.

Salamonson Y, Weaver R, Chang S, Koch J, Bhathal R, Khoo C \& Wilson I (2013) Learning approaches as predictors of academic performance in first year health and science students. Nurse education today 33(7): 729-733.

Schaffer S, Doggrell S, Polkinghorne A \& Tuli R (2014) A loss of bioscience knowledge in nursing students.

Smales K (2010) Learning and applying bioscience to clinical practice in nursing. Nursing Standard (through 2013) 24(33): 35 .

Taylor V, Ashelford S, Fell P \& Goacher PJ (2015) Bioscience in nurse education: is the curriculum fit for practice? Lecturers' views and recommendations from across the UK. Journal of clinical nursing 24(19-20): 2797-2806.

Online dictionary. Available on http://www. merriamwebster. comdictionary. 